\title{
Aggression on Inpatient Units: Clinical Characteristics and Consequences
}

Laoise RENWICK ${ }^{1,2}$, Lecturer, RMN, BNS, PhD

Duncan STEWART ${ }^{4}$, Senior Lecturer, BA, PhD

Michelle RICHARDSON ${ }^{5}$, Post-doctoral Researcher, BA, MRes, DPhil

Mary LAVELLE ${ }^{1}$, Post-doctoral Researcher, BSc (Hons), MSc, PhD

Karen JAMES ${ }^{1}$, Research Worker, BA, MSc

Claire HARDY ${ }^{3}$, Post-doctoral Researcher, BSc (Hons), MSc, PhD

Owen PRICE ${ }^{2}$, Research Fellow, RMN, BSc, MSc

Len BOWERS ${ }^{1}$, Professor of Mental Health Nursing, RMN, PhD

${ }^{1}$ Section of Mental Health Nursing, Health Service and Population Research, Institute of Psychiatry, Psychology and Neuroscience, Kings College London

${ }^{2}$ School of Nursing, Midwifery and Social Work, University of Manchester

${ }^{3}$ Health Psychology Section, Institute of Psychiatry, Psychology and Neuroscience, Kings College London

${ }^{4}$ School of Psychology, Social Work and Human Sciences, University of West London

${ }^{5}$ Department of Childhood, Families and Health, Institute of Education, University College London

* corresponding author

Dr. Laoise Renwick, Room 6.304 Jean MacFarlane Building, University of Manchester, Oxford Road M139PL. Tel: 01613067833

Accepted 22 September 2015 


\section{Introduction}

Violence and aggression on psychiatric inpatient units is a widespread problem throughout the UK. Approximately $40 \%$ of inpatients display aggression in some form; a rate that is higher than those found in other European and international studies (Bowers, Stewart et al. 2011). Although UK policy to reduce restrictive interventions and deliver crisis care safely has taken centre stage, the reduction of aggression is a key issue and an inescapable reality of mental health treatment. Aggression takes many forms ranging from verbal abuse and threats to physical violence. All types have the potential to be hazardous for both staff and other patients as have the containment methods used to manage aggression. Indeed, interventions such as manual restraint, enforced medication and seclusion are often unpalatable for both the staff implementing them and the patients who are subject to them (El-Badri and Mellsop 2008). Moreover, the immediate aftermath of aggression and violence can result in physical injury to staff (Omérov, Edman et al. 2002; Daffern, Ogloff et al. 2003; Gerberich, Church et al. 2004; Langsrud, Linaker et al. 2007) while negative psychological outcomes such as increased anxiety, symptoms of post-traumatic stress and reduced job satisfaction (Whittington and Wykes 1994; Flannery and Walker 2001; Flannery and Walker 2008) may emerge in victims more steadily over time. At a macro level, the incidence of aggression and violence and management methods intended to contain such events is costly to the state. Estimates indicate a mean annual cost of around $£ 72$ million for conflict (Flood, Bowers et al. 2008); a quarter of this is attributed to incidents of aggression including verbal and physical violence. Hence the detrimental effect of increasing aggression on patient care from both direct and indirect means is becoming increasingly apparent.

Patient factors that affect rates of aggression and violence on inpatient units include minority ethnicity (Kho, Sensky et al. 1998; El-Badri and Mellsop 2008), involuntary detention (Bowers, Allan et al. 2007; Biancosino, Delmonte et al. 2009), male gender (Daffern, Ogloff et al. 2003; Biancosino, Delmonte et al. 2009), history of violent behaviour (Owen, Tarantello et al. 1998; Grassi, Biancosino et al. 2006), younger age (Raja, Azzoni et al. 1997; Grassi, Peron et al. 2001; Soliman and Reza 2001) and a history of illicit substance use (Blomhoff, Seim et al. 1990; Soliman and Reza 2001; Daffern, 
Ogloff et al. 2003). Some studies have also found a higher risk of violence and aggression displayed by those with specific psychiatric diagnoses such as schizophrenia and antisocial personality disorder (Raja, Azzoni et al. 1997; Mellesdal 2003). Despite this, patient factors are not the sole determinants of violence and aggression on inpatient units. There is likely a confluence of contributory factors including staff variables, structure (rules and routines), features of the physical environment, mental health legislation and the impact of external influences such as family stressors (Bowers, Alexander et al. 2014). It is important to note that patient-staff interaction provides a complex set of circumstances for an increased occurrence of aggression contributing to $39 \%$ of violent and aggressive incidents (Bowers, Ross et al. 2012; Papadopoulos, Ross et al. 2012). However, aggressive incidents are often evaluated from one dimension and dichotomised as being present or absent rather than appreciating the complex situational variables that can affect the outcome of an aggressive incident.

Given this, exploring aggressive incidents disaggregated from the incidents that precede or follow them provides a narrow snapshot of the pathway of these incidents and their subsequent management. Taking this into account, we examined the incidence of aggressive events among a sample of patients admitted to acute psychiatric settings during the first two weeks of admission. As different types of aggression may vary in severity and consequence (Stewart and Bowers 2013) we examined whether patient factors are different when aggression has been separated by type i.e. verbal and physical. We classified sequences of events based on the amount and type of conflict and containment that evolved before and after each aggressive incident. We also examined whether patient level factors were linked with differences in the way conflict behaviours and containment grouped together. We anticipated that more severe forms of aggression would show greater links with containment measures i.e. deescalation, enforced medication, manual restraint and seclusion and that less severe incidents would likely resolve without further intervention.

\section{Method}

\section{Study Setting and Participants}


This study was conducted in 31 hospitals in South England using data from patients admitted to 84 mental health inpatient units. The purpose was to collect detailed information on the sequence of events occurring before and after incidents of conflict and containment to examine potential targets and opportunities for better management of aggression and violence. Participants were recruited by researchers visiting inpatient units in participating hospitals on a number of occasions between July 2009 and March 2010. On the visit in question, researchers obtained a random sample of a maximum of 6 patients from the unit population if they were over 18, had been an inpatient longer than 2 weeks and if they were available to give consent at the time of the visit. Unit staff then advised on whether patients within the sample chosen were deemed well enough to appreciate the study as it was presented to them and were able to give consent to enter into the study. An agreed minimum of 3 patients per ward and 20 patients per hospital was the target. There were 1902 eligible patients of which 973 were deemed too ill by staff to consent to the study. 407 patients refused to participate leaving 522 patients across different inpatient units which are reported here. Other analyses and findings from this study have been published elsewhere (Bowers, Ross et al. 2012; Stewart and Bowers 2013; Bowers, Ross et al. 2014; Stewart and Bowers 2015).

\section{Measures and Procedures}

Once consent was obtained, retrospective case note review was conducted to record patient socio-demographic characteristics and illness characteristics. The following variables were obtained; age, gender, marital status, living situation, marital status, ethnicity, ICD-10 diagnoses, type of admission (first versus multiple), history of alcohol and illicit substance misuse, history or threat of self-harm and history or threat of violence. Case note reviewers also catalogued instances of conflict and containment using the Patient Conflict Checklist (PCC) (Bowers, Douzenis et al. 2005) which comprises a schedule of 21 conflict items and 9 containment methods. These were documented within a single shift period for the first two weeks of the participant's admission. Conflict is defined as behaviours likely to harm patients or others and containment is defined as staff actions intended to protect patients and others from harm (see Appendix).The PCC is manualised with each conflict and 
containment event accompanied by a precise definition. An earlier study reported good inter-rater reliability using the PCC (Bowers, Douzenis et al. 2005).

Verbal aggression was defined as loud noises, angry shouting, personal insults, cursing, foul language, threats, of a sufficient duration, intensity or volume that you would usually mention it in the nursing notes of the patient. Physical aggression against objects included slamming doors, making a mess, throwing things, kicking things, breaking things and setting fires and physical aggression against others included swings at people, grabbing them, strikes, kicks, pushes, pulling hair and physical attacks. These data were collected by 2 university researchers and 18 Mental Health Research Network Clinical Studies Officers (MHRN CSOs). The university researchers provided specific training to the CSOs on the study aim, sampling frame, data collection procedures and operationalization of definitions of constructs used within the study. Practice cases comprised between 3 and 5 hypothetical case vignettes that were developed for training purposes and were completed by all CSOs. The study was approved by Kings College Hospital Research Ethics Committee.

\section{Statistical Analysis}

Demographic and clinical data were compared using Chi-square tests to examine whether there were differences between patients who displayed no aggression and those who did on each of the outcome measures; verbal aggression, physical aggression against objects and physical aggression against others. Among those who displayed some form of aggression, there were 1422 incidents of aggression during shifts comprising sequences of conflict with or without conflict and containment antecedents and consequences (aggression sequences). We grouped the individual conflict and containment event types into higher order categories to facilitate analysis: aggression, rule-breaking, absconding, medication, self-harm, containment, substance use and end of containment (see Appendix). We then used two step cluster analysis on single shift units containing aggressive behaviours to identify different types of sequences of events that included aggression. Cluster analysis 
is a multivariate procedure for grouping individuals or objects into clusters based on statistical distance algorithms.

The initial step of the two step process involved identifying pre-clusters which were then used in a hierarchical cluster analysis in place of raw data. Each step requires only one pass through the data rather than examining the distances between all pairs in the data. This is acceptable when using continuous variables that are normally distributed and independent (Bacher, Wenzig et al. 2004; Noruésis 2011). To ensure this was the case we calculated each input variable by expressing the variable as a proportion of each higher order category in the sequence and determined that correlations between these newly created variables were modest (correlations did not exceed $r=.26$ ). As an exploratory procedure without definitive methods for determining the number of clusters, we followed recommendations of Everitt and colleagues (2011) using multiple methods to determine the optimal number of clusters. We performed the initial cluster analysis and events that contributed least to the identification of cluster membership by virtue of low occurrence rates in the sequences of conflict and containment were removed. The remaining variables (aggression, rule-breaking, medication and containment) were entered into a cluster analysis with the squared Euclidian distance chosen as a measure of similarity (Everitt, Landau et al. 2011). We performed a number of checks to confirm cluster stability and to reduce the influence of subjectivity on the determination of clusters. Firstly, we repeated the cluster analysis on two randomly selected subsets of the data representing approximately $50 \%$ of the data in each subset to determine if the four cluster solution was similar in both subsets. We then performed the cluster analysis on the complete sample specifying a maximum three and five cluster solution and inspected the cluster solution output to make sure that each alternative solution did not provide a better fit for the data (Hair, Black et al. 2010).

To determine criterion validity of the clusters obtained, we examined the relationships between patient-level demographic and clinical variables and the clusters. In many cases there were several sequences per patient so cluster membership was compared with cases in the entire sample that were not in the cluster being tested i.e. a patient that may have exhibited aggression in one cluster may have been compared with patients with aggression in a different cluster and patients with no 
aggression at all. A series of logistic regression models were performed to determine independent predictors of the likelihood of cluster membership in each of the four clusters using variables that significantly discriminated between cluster membership during bivariate analysis. The following variables were considered as possible explanatory variables: age, ethnicity, living status, admission status, history of alcohol/substance use, history of self-harm and history of violence. The explanatory variables were entered as covariates using the forward entry method. Unadjusted odds ratios and confidence intervals are reported for each explanatory variable in each model. Statistical analyses were conducted using IBM SPSS version 21.

To summarise, we had data on events occurring before and after 1422 incidents of aggression. We simplified these events by grouping them into a number of different higher order categories (e.g. attempted absconding, missing without permission, and officially reported absconding were all grouped as 'absconding'). We then sought to identify an underlying typology of sequences using cluster analysis. Once we had that typology, we explored statistically how it was related to patient factors.

\section{Results}

\section{Sample Characteristics}

There were 522 patients included in this study, over half of which were male ( $n=279$, 53.4\%). The average age of participants was 41.1 years $(S D=13.0)$ and there was no age difference between genders $(t(518)=-1.58, p=.114)$. The majority of participants were white British $(n=352$, $67 \%)$ and those in the minority groups were younger $(M=36.2, S D=11.9)$ than British participants $(M=43.5, S D=13.0 ; t(518)=6.10, p<.001)$. Minority ethnicities were predominantly black comprising black Caribbean $(n=26,5 \%)$, black African $(n=26,5 \%)$ and other black $(n=25,5 \%)$. Few were currently married $(n=96,18 \%)$ and approximately a third lived alone prior to admission (n $=189,36 \%)$. High proportions of participants were experiencing either a Psychotic Disorder $(n=219$, $42 \%)$ or a Mood Disorder $(n=191,37 \%)$ and ten percent $(n=54)$ were assigned a diagnosis of Personality Disorder. A small proportion of participants were first admissions $(n=77,15 \%)$ while the 
remainder had been admitted on at least one other occasion prior to the admission under investigation in this study $(n=438,84 \%)$. Among the sample, there were high levels of having a history of actual or threatened self-harm $(n=327,63 \%)$ and similarly, there were high levels of having a history of actual or threatened violence against others $(n=296,57 \%)$. There were more moderate levels of historical problem alcohol use $(n=202,39 \%)$ and illicit substance use among the sample $(n=189$, $36 \%)$.

\section{Aggression}

As observable from Table 1, there were varying proportions of patients who displayed some form of aggression during the first two weeks of admission. Verbal aggression was the commonest type of aggression displayed by patients on at least one occasion $(n=264,51 \%)$ followed by aggression against objects $(n=130,25 \%)$ and physical aggression towards others $(n=106,20 \%)$. Overall, there were $291(56 \%)$ patients who displayed at least one of the three forms of aggression and a minority displayed all three at some stage during early admission $(n=59,11 \%)$. For those who displayed aggression, the average number of events reported during the two week period of the study was $4.9(S D=4.9$, Min. = 1, Max. = 28). Again, as can be seen in Table 1, there are several sociodemographic differences between patients who are physically aggressive towards others. These data show they are typically younger, are in the ethnic majority and were more likely to live alone preceding admission indicating poor social support available. There were no statistical differences in demographics in those displaying other forms of aggression. Regarding clinical factors, both illicit substance use and history of violence were present in higher rates among those displaying all types of aggression. There were no other clinical factors that were more consistently found in all types of aggression. 
Table 1: Socio-demographic and Clinical Characteristics Compared by Aggression Type

\begin{tabular}{|c|c|c|c|c|c|c|}
\hline \multirow{2}{*}{$\begin{array}{l}N=522 \\
\text { Demographic Information }\end{array}$} & \multicolumn{2}{|c|}{$\begin{array}{l}\text { Verbal Aggression } \\
\quad(n=264)\end{array}$} & \multicolumn{2}{|c|}{$\begin{array}{c}\text { Physical Aggression } \\
\text { Against Objects }(n=130)\end{array}$} & \multicolumn{2}{|c|}{$\begin{array}{c}\text { Physical Aggression } \\
\text { Against Others }(n=106)\end{array}$} \\
\hline & $\begin{array}{l}\text { Mean } \\
(S D)\end{array}$ & $t$-test & $\operatorname{Mean}(S D)$ & $t$-test & $\operatorname{Mean}(S D)$ & $t$-test \\
\hline \multicolumn{7}{|l|}{ Age } \\
\hline Yes & $40.3(12.9)$ & -1.33 & $40.1(12.7)$ & -0.95 & $38.2(12.3)$ & $-2.60^{* *}$ \\
\hline \multirow[t]{2}{*}{ No } & $41.9(13.2)$ & & $41.4(13.2)$ & & $41.8(13.1)$ & \\
\hline & $n(\%)$ & $X^{2}$ & $n(\%)$ & $X^{2}$ & $n(\%)$ & $X^{2}$ \\
\hline \multicolumn{7}{|l|}{ Gender } \\
\hline Male & $150(56.8)$ & 2.44 & $71(54.6)$ & 0.13 & $61(57.5)$ & 0.98 \\
\hline Female & $114(43.2)$ & & $59(45.4)$ & & $45(42.5)$ & \\
\hline \multicolumn{7}{|l|}{ Marital Status } \\
\hline Married & $49(18.6)$ & 0.01 & $25(19.4)$ & 0.05 & $24(22.6)$ & 1.52 \\
\hline Not Married & $214(81.4)$ & & $104(80.6)$ & & $82(77.4)$ & \\
\hline \multicolumn{7}{|l|}{ Ethnicity } \\
\hline Majority & $170(64.9)$ & 1.65 & $80(62.0)$ & 2.35 & $59(56.2)$ & $8.00^{* *}$ \\
\hline Minority & $92(35.1)$ & & $49(38.0)$ & & $46(43.8)$ & \\
\hline \multicolumn{7}{|l|}{ Living Status } \\
\hline Alone & $100(40.7)$ & 2.36 & $46(38.0)$ & 0.71 & $39(39.4)$ & $9.75^{* *}$ \\
\hline Others & $122(49.6)$ & & $63(52.1)$ & & $57(57.6)$ & \\
\hline No Fixed Abode & $24(9.8)$ & & $12(9.9)$ & & $3(3.0)$ & \\
\hline \multicolumn{7}{|l|}{ Clinical Characteristics } \\
\hline \multicolumn{7}{|l|}{ First Admission } \\
\hline Yes & $29(11.1)$ & $6.14^{*}$ & $16(12.4)$ & 0.35 & $12(11.3)$ & 1.38 \\
\hline No & $232(88.9)$ & & $113(87.6)$ & & $94(88.7)$ & \\
\hline \multicolumn{7}{|l|}{ Alcohol Use } \\
\hline Yes & $111(56.8)$ & 2.44 & $53(42.4)$ & 0.45 & $46(44.7)$ & 1.25 \\
\hline No & $146(43.2)$ & & $72(57.6)$ & & $57(55.3)$ & \\
\hline \multicolumn{7}{|l|}{ Illicit Substance Use } \\
\hline Yes & $108(58.3)$ & $5.45^{*}$ & $56(44.1)$ & $3.89^{*}$ & $48(46.6)$ & $5.36^{*}$ \\
\hline No & $151(41.7)$ & & $71(55.9)$ & & $55(53.4)$ & \\
\hline \multicolumn{7}{|l|}{ History/Threat Self-harm } \\
\hline Yes & $147(43.5)$ & $10.54^{* * *}$ & $76(59.4)$ & 0.28 & $62(59.0)$ & 1.06 \\
\hline No & $113(56.5)$ & & $52(40.6)$ & & $43(41.0)$ & \\
\hline \multicolumn{7}{|l|}{ History/Threat Violence } \\
\hline Yes & $180(68.7)$ & $28.45^{* * *}$ & $95(73.1)$ & $17.77^{* * *}$ & $77(72.6)$ & $12.90^{* * *}$ \\
\hline No & $82(31.3)$ & & $35(26.9)$ & & $29(27.4)$ & \\
\hline \multicolumn{7}{|l|}{ Diagnosis } \\
\hline Psychotic Disorders & $122(46.2)$ & 5.28 & $56(43.1)$ & 0.61 & $47(44.3)$ & 0.42 \\
\hline Mood Disorders & $94(35.6)$ & & $44(33.8)$ & & $37(34.9)$ & \\
\hline Personality Disorders & $21(8.0)$ & & $14(10.8)$ & & $11(10.4)$ & \\
\hline Other & $27(10.2)$ & & $16(12.3)$ & & $11(10.4)$ & \\
\hline
\end{tabular}

Note 1 Significant at the level of $p<.05{ }^{* * *}$ Significant at the level of $p<.01{ }^{* * * *}$ Significant at the level of $p<$ .001 . 


\section{Cluster Analysis}

Descriptive statistics revealed 370 different sequences of conflict and/or containment among the 1422 sequences of aggression. Two-step cluster analysis yielded a four cluster solution as specified based on BIC change > 10 (Fraley and Raftery 1998). Solo Aggression contained single episodes of aggression where there was only one incident of aggression and no events before or after. In a few cases there was more than one aggressive incident which may have been two different types of aggression at once but there were still no other forms of conflict and containment in this cluster. Aggression-Rule-breaking contained sequences characterised by moderate aggression and rulebreaking alongside the aggressive incident. Examples of rule-breaking include refusal to observe ward rules, refusal to maintain self-care, exposing self or smoking in a no-smoking area. AggressionContainment comprised sequences with aggression and some form of containment alongside the aggression, either before or after or in a repeated manner. The containment methods included ranged from non-invasive forms such as de-escalation to physical interventions such as manual restraint and enforced medication. The last cluster identified was Aggression-Medication. This comprised sequences characterised by an aggressive incident and some form of conflict regarding medication that either precipitated the incident or where medication was used to contain the event.

Over a third of the sequences belonged to the Aggression-Containment cluster $(n=564,40 \%)$ which was the only cluster characterised by high levels of containment. The next largest cluster was Solo-Aggression $(n=419,30 \%)$ and both Aggression-Rule-breaking $(n=214,15 \%)$ and AggressionMedication $(n=225,16 \%)$ had fewer sequences in them. When we looked at the amount of times each patient displayed a particular type of aggression by cluster, just under three quarters of the sample that displayed some aggression had more than one cluster $(n=216,74 \%)$ meaning that patients did not tend to display one type of aggression alone even if it was repeated. Table 2 compares all those patients who displayed behaviours fitting a cluster type with all other patients. For example, the mean age of those patients who showed at least one Solo Aggression type sequence was 41.3 years, and all those patients not displaying this sequence had an average age of 40.6 years. This difference was not significant $(p=.564)$. 
Table 2: Socio-demographic and Clinical Characteristics Compared by Aggression Type

\begin{tabular}{|c|c|c|c|c|c|c|c|c|}
\hline \multirow{2}{*}{$\begin{array}{l}=522 \\
\begin{array}{l}\text { Demographic } \\
\text { Information }\end{array}\end{array}$} & \multicolumn{2}{|c|}{$\begin{array}{l}\text { Solo Aggression } \\
\quad(n=179)\end{array}$} & \multicolumn{2}{|c|}{$\begin{array}{l}\text { Aggression- } \\
\text { Rulebreaking } \\
\quad(n=110)\end{array}$} & \multicolumn{2}{|c|}{$\begin{array}{l}\text { Aggression-Containment } \\
\qquad(n=214)\end{array}$} & \multicolumn{2}{|c|}{$\begin{array}{c}\text { Aggression- } \\
\text { Medication } \\
(n=116)\end{array}$} \\
\hline & Mean $(S D)$ & $t$ & $\operatorname{Mean}(S D)$ & $t$ & Mean (SD) & $t$ & Mean $(S D)$ & $t$ \\
\hline \multicolumn{9}{|l|}{ Age } \\
\hline Yes & $41.3(13.1)$ & 0.58 & $38.1(13.5)$ & $2.71^{* *}$ & $38.3(12.5)$ & $4.10^{* * *}$ & $38.2(12.4)$ & $2.66^{* *}$ \\
\hline No & $\begin{array}{c}40.6(13.0) \\
n(\%)\end{array}$ & $X^{2}$ & $\begin{array}{c}41.1(12.8) \\
n(\%)\end{array}$ & $X^{2}$ & $\begin{array}{c}43.0(13.2) \\
n(\%)\end{array}$ & $X^{2}$ & $\begin{array}{c}41.8(13.1) \\
n(\%)\end{array}$ & $X^{2}$ \\
\hline \multicolumn{9}{|l|}{ Gender } \\
\hline Male & $104(58.1)$ & 2.57 & $62(56.4)$ & 0.54 & $118(55.1)$ & 0.52 & $66(56.9)$ & 0.79 \\
\hline Female & $75(41.9)$ & & $48(43.6)$ & & $96(44.9)$ & & $50(43.1)$ & \\
\hline \multicolumn{9}{|l|}{ Marital Status } \\
\hline Married & $34(19.0)$ & 0.02 & $18(16.4)$ & 0.50 & $34(16.0)$ & 1.77 & $18(15.5)$ & 1.00 \\
\hline Not Married & $145(81.0)$ & & $92(83.6)$ & & $179(84.0)$ & & $98(84.5)$ & \\
\hline \multicolumn{9}{|l|}{ Ethnicity } \\
\hline Majority & $112(62.9)$ & 2.59 & $57(52.8)$ & $13.47^{* * *}$ & $126(59.2)$ & $11.45^{* * *}$ & $62(54.4)$ & $11.45^{* * *}$ \\
\hline Minority & $66(37.1)$ & & $51(47.2)$ & & $87(40.8)$ & & $52(45.6)$ & \\
\hline \multicolumn{9}{|l|}{ Living Status } \\
\hline Alone & $68(41.2)$ & 1.01 & $40(39.2)$ & 0.02 & $87(42.9)$ & 2.72 & $51(48.1)$ & $6.83^{*}$ \\
\hline Others & $80(48.5)$ & & $50(49.0)$ & & $93(45.8)$ & & $48(45.3)$ & \\
\hline No Fixed Abode & $17(10.3)$ & & $12(11.8)$ & & $23(11.3)$ & & $7(6.6)$ & \\
\hline \multicolumn{9}{|l|}{ Clinical Characteristics } \\
\hline \multicolumn{9}{|l|}{ First Admission } \\
\hline Yes & $15(8.4)$ & $9.11^{* *}$ & $13(11.8)$ & 1.08 & $28(13.1)$ & 0.93 & $9(7.8)$ & $5.91^{*}$ \\
\hline No & $163(91.6)$ & & $97(88.2)$ & & $185(86.4)$ & & $106(92.2)$ & \\
\hline \multicolumn{9}{|l|}{ Alcohol Use } \\
\hline Yes & $74(42.8)$ & 0.94 & $42(38.9)$ & 0.05 & $94(45.9)$ & $5.19^{*}$ & $46(40.7)$ & 0.05 \\
\hline No & $99(57.2)$ & & $66(61.1)$ & & $111(54.1)$ & & $67(59.3)$ & \\
\hline \multicolumn{9}{|l|}{ Illicit Substance Use } \\
\hline Yes & 79 (44.9) & $7.58^{* *}$ & $55(50.9)$ & $11.78^{* * *}$ & $102(49.0)$ & $22.62^{* * *}$ & $60(52.2)$ & $15.12^{* * *}$ \\
\hline No & $97(55.1)$ & & $53(49.1)$ & & $106(51.0)$ & & $55(47.8)$ & \\
\hline \multicolumn{9}{|l|}{$\begin{array}{l}\text { History/Threat Self- } \\
\text { harm }\end{array}$} \\
\hline Yes & $100(56.5)$ & $5.49^{*}$ & $61(56.0)$ & 3.27 & $125(59.8)$ & 1.92 & $62(53.4)$ & $6.35^{*}$ \\
\hline No & $77(43.5)$ & & $48(44.0)$ & & $84(40.2)$ & & $54(46.6)$ & \\
\hline \multicolumn{9}{|l|}{ History/Threat Violence } \\
\hline Yes & $133(74.7)$ & $33.84^{* * *}$ & $84(76.4)$ & $20.85^{* * *}$ & $164(77.4)$ & $59.35^{* * *}$ & $91(78.4)$ & $27.45^{* * *}$ \\
\hline No & $45(25.3)$ & & $26(23.6)$ & & $48(22.6)$ & & $25(21.6)$ & \\
\hline \multicolumn{9}{|l|}{ Diagnosis } \\
\hline Psychotic Disorders & $80(44.7)$ & 1.46 & $49(44.5)$ & 6.35 & $92(43.0)$ & 4.23 & $52(44.8)$ & 4.49 \\
\hline Mood Disorders & $65(36.3)$ & & $36(32.7)$ & & $83(38.8)$ & & $46(39.7)$ & \\
\hline Personality Disorders & $16(8.9)$ & & $17(15.5)$ & & $22(10.3)$ & & $11(9.5)$ & \\
\hline Other Diagnosis & $18(10.1)$ & & $8(7.3)$ & & $17(7.9)$ & & $7(6.0)$ & \\
\hline
\end{tabular}


There were some notable findings in Table 2. Although the sample contained a higher number of British participants $(n=351,68 \%)$, there were higher proportions of participants from ethnic minorities in three out of four aggression clusters. For example, over half of ethnic minority participants showed aggression in the Aggression-Containment cluster $(n=87,52 \%)$ versus just over a third of British participants $(n=126,36 \%)$. This means that people in ethnic minorities were more likely than British participants to display aggression that was accompanied by containment. They were also more likely to show aggression accompanied by rule-breaking or conflict around medication and although the finding was non-significant $(p=.066)$ there was a trend towards a higher level of Solo-aggression displayed by ethnic minorities. Similarly, these same clusters were more frequently displayed in patients who were younger. Those in ethnic minorities were significantly younger than British participants $(M=36.2, S D=11.8$ vs $M=43.4, S D=13.0, t(518)=6.11, p<$ .001). In clinical outcomes, participants more likely to display aggression in any of the clusters had a prior history of both substance use and violence. Those with a history of self-harm were more likely to display aggression on its own or have either conflict around medication or aggressive incidents displayed by this group were managed more often with medication. This was also true of first admissions versus repeated admission participants. 
Table 3: Predictors of Cluster Membership

\begin{tabular}{|c|c|c|c|c|}
\hline \multirow[b]{2}{*}{ Explanatory Variables } & \multirow[t]{2}{*}{$B(S E)$} & \multirow[t]{2}{*}{$\operatorname{Exp}(B)$} & \multicolumn{2}{|c|}{$95 \%$ CI for $\operatorname{Exp}(B)$} \\
\hline & & & Lower & Upper \\
\hline & \multicolumn{4}{|c|}{ Solo-Aggression } \\
\hline First admission & $-0.79(0.32)^{*}$ & 0.50 & 0.25 & 0.84 \\
\hline History of illicit substance use & $0.27(0.21)$ & 1.31 & 0.87 & 1.96 \\
\hline History of threatened or actual self-harm & $-0.37(0.20)$ & 0.69 & 0.47 & 1.03 \\
\hline \multirow[t]{2}{*}{ History of threatened or actual violence } & $1.06(0.22)^{* * *}$ & 2.89 & 1.90 & 4.41 \\
\hline & \multicolumn{4}{|c|}{ Aggression-Rulebreaking } \\
\hline Age & $-0.01(0.01)^{* *}$ & 0.01 & 0.01 & 0.24 \\
\hline Ethnicity & $0.56(0.24)^{*}$ & 1.75 & 1.10 & 2.78 \\
\hline History of illicit substance use & $0.36(0.25)$ & 1.43 & 0.88 & 2.33 \\
\hline \multirow[t]{2}{*}{ History of threatened or actual violence } & $0.83(0.26)^{* * *}$ & 2.30 & 1.39 & 3.81 \\
\hline & \multicolumn{4}{|c|}{ Aggression-Containment } \\
\hline Age & $-0.02(0.01)$ & 0.98 & 0.97 & 1.00 \\
\hline Ethnicity & $0.23(0.22)$ & 1.26 & 0.83 & 1.93 \\
\hline History of alcohol abuse & $0.05(0.22)$ & 1.05 & 0.69 & 1.61 \\
\hline History of illicit substance use & $0.38(0.23)$ & 1.46 & 0.93 & 2.30 \\
\hline \multirow[t]{2}{*}{ History of threatened or actual violence } & $1.30(0.22)^{* * *}$ & 3.66 & 2.41 & 5.56 \\
\hline & \multicolumn{4}{|c|}{ Aggression-Medication } \\
\hline Age & $-0.02(0.01)$ & 0.99 & 0.97 & 1.00 \\
\hline Ethnicity & $0.29(0.22)$ & 1.33 & 0.87 & 2.04 \\
\hline Living alone & $0.60(0.48)$ & 1.82 & 0.72 & 4.62 \\
\hline Living with others & $0.39(0.47)$ & 1.48 & 0.59 & 3.74 \\
\hline No fixed abode & $0.09(0.53)$ & 1.10 & 0.39 & 3.13 \\
\hline First admission & $-0.22(0.30)$ & 0.80 & 0.45 & 1.41 \\
\hline History of illicit substance use & $0.45(0.22)^{*}$ & 1.57 & 1.02 & 2.42 \\
\hline History of threatened or actual self-harm & $-1.44(0.21)$ & 0.87 & 0.58 & 1.31 \\
\hline History of threatened or actual violence & $1.32(0.21)^{* * *}$ & 3.74 & 2.46 & 5.69 \\
\hline
\end{tabular}

Note 2 Significant at the level of $\mathrm{p}<.05{ }^{* * *}$ Significant at the level of $\mathrm{p}<.01{ }^{* * * *}$ Significant at the level of $\mathrm{p}<$ .001 .

Testing logistic regression models against constant only models revealed that the set of predictors in each model reliably distinguished between cluster membership for Solo-Aggression $\left(X^{2}{ }_{4}\right.$ $=46.9, p<.001$, Cox \& Snell $\left.R^{2}=.123\right)$, Aggression-Rule-breaking $\left(X^{2}{ }_{4}=31.7, p<.001\right.$, Cox \& Snell $\left.R^{2}=.094\right)$, Aggression-Containment $\left(X^{2}{ }_{5}=72.8, p<.001\right.$, Cox \& Snell $\left.R^{2}=.182\right)$ and AggressionMedication $\left(X^{2}{ }_{9}=80.3, p<.001\right.$, Cox \& Snell $\left.R^{2}=.200\right)$. Table 3 details the unadjusted odds ratios for the models and indicates which explanatory variables were significant predictors in each model. To determine whether the influence of ethnicity could be explained by age we repeated the models to control for the influence of ethnicity. In each model, ethnicity did not contribute significantly to the prediction of cluster membership with the exception of Aggression-Rule-breaking ( $p=.019)$. 


\section{Discussion}

In this study we examined whether distinct profiles could be determined from sequences of conflict and containment on acute inpatient psychiatry wards. To our knowledge, this type of analysis has not been reported previously on episodes of inpatient aggression. The principal finding was that sequences can be successfully classified into clusters on the basis of common characteristics within, namely aggression, implementing containment interventions, conflict surrounding medication and rule-breaking. We found other forms of conflict (absconding, self-harm, substance use) contributed less to the classification of aggression and were less significant when categorising event sequences. This does not invalidate previous findings that conflict behaviours such as these disrupt treatment and hinder recovery (Ross, Bowers et al. 2012) but tells us which sequences are similar and which conflict and containment events are linked in similar groups.

The finding that those who display physical aggression during early admission are also more likely to exhibit a Solo-Aggression suggests that those who are physically aggressive also regularly engage in non-physical aggression that is not followed by further conflict and containment events. This finding may suggest variation in aggression management approaches between individual nursing staff in mental health inpatient wards in the south of England. Whilst it is possible that these differences in incident trajectories may be explained by patient level factors not included here (fluctuations in mental state and specific situational differences), it is also possible that they reflect differences in individual nursing management of aggressive behaviour. Lending support to our interpretation that behavioural management may differ is the observation that those who were violent toward objects were more likely to be classified in both the Solo-Aggression cluster as well as the Aggression-Containment cluster. This is also supported by descriptive findings that there were sizeable portions of the sequences in all aggression categories that were not followed by any containment intervention. This is consistent with literature showing wide variation in the use of coercive containment methods for aggressive behaviour with roughly a fifth of samples subject to seclusion (Owen, Tarantello et al. 1998; Steinert 2002; Foster, Bowers et al. 2007) and higher proportions subject to manual restraint (Dowson, Butler et al. 1999) and non-routine sedative 
medications (Gudjonsson, Rabe-hesketh et al. 1999; Foster, Bowers et al. 2007). There is corresponding wide variation in the literature on aggressive events where no consequences follow. Rates of no management consequence vary from $2 \%$ to $44 \%$ of generic adult populations (Grassi, Peron et al. 2001; Grassi, Biancosino et al. 2006; Foster, Bowers et al. 2007; Langsrud, Linaker et al. 2007). This strongly suggests differences among nurses in decisions to use containment or more passive intervention in response to different aggression types, which is a plausible explanation for our findings.

The finding that physical aggression did not dominate in terms of association with containment was striking, and we offer two possible interpretations. Either nurses are pre-emptively using containment measures to successfully avert physical aggression before it occurs, or nurses are sometimes relying on using containment methods to manage low-risk aggression. Our finding that containment methods tended to conclude aggression sequences does not support the first assertion and we propose the second holds more weight. It seems more likely that there are inconsistent thresholds for the use of more restrictive interventions such as manual restraint and seclusion. This is a particularly pertinent issue in terms of the recent UK context. Serious concerns have been raised about the routine use of manual restraint to manage mental health crises (MIND 2013) despite longstanding clinical guidelines emphasising usage only as last resort (NICE 2015). Recent initiatives including the Safewards model (Bowers 2014) have made progress in identifying a knowledge base of effective interventions to offset some of these problems.

In terms of patient factors linked with aggression, variables predicting an elevated risk of physical aggression consistent with previous literature included younger age, illicit substance usage, and history of violence (Bowers, Stewart et al. 2011). However, a more troubling finding was that ethnic minority membership was associated with an increased risk of physical aggression. Although this finding has been replicated elsewhere (Bowers, Douzenis et al. 2005; Large and Nielssen 2011), metaanalyses suggest no difference between ethnic majority and minority groups in terms of rates of violence and aggression (Bowers, Stewart et al. 2011) or in rates of containment (Stewart, Bowers et al. 2009; van der Mewe, Bowers et al. 2009). We found evidence that this relationship may be 
mediated by age as ethnicity did not explain aggression clusters once age was removed from the models. Younger age was associated with all clusters except Solo-Aggression, suggesting a reduced capacity among younger patients to regulate aggressive impulses and thus avoid escalation to further conflict and/or containment events. This may be explained in a number of ways. Firstly, there may be greater acuity in the symptom profile of younger patients. An example is patients with first episode psychosis (predominantly younger) who are at an elevated risk of violence compared with more chronically psychotic (and, therefore, older) patients (Látalová 2014). Secondly, younger age, in itself, is associated with increased risk of violence because capacity for emotional self-regulation increases with age (Labouvie-Vief 2003). Thirdly, young age-related themes such as the desire for independence, freedom and liberty have been found to have an important bearing on violence in inpatient settings (Bowers, Alexander et al. 2014) and capacity for self-regulation may be compromised during events that threaten these needs.

A further finding was that aggression was common in this sample with over half displaying some form of aggression and are in excess of typical rates reported between 10 and 15\% (Cornaggia, Beghi et al. 2011). This is possibly due to our inclusion of a wide definition of aggression which increases reported rates (Abderhalden, Needham et al. 2007) but could also be due to our concentration on the early phase of the admission which is associated with more dangerous behaviour (Carr, Lewin et al. 2008). Another possibility is that there were a number of patients declining invitations to participate in the study and generalisability may be somewhat compromised as can be the case given we have focused our data collection in the south of England and wide geographical variation exists in ethnicity. Additionally, there may be other variables impacting aggression rates that were not within the scope of the study such as comorbidity of medical conditions or developmental disorders. Despite this, the study was permissible due to the use of a large sample that characterises different aggression sequences on inpatient units in the south of England and should be considered to represent the behavioural sequelae to aggression for both patients and staff.

In summary, we found that aggression sequences differed but could be grouped together based on the events before and after. We highlighted that this variation was not explained by the type and hence 
severity of the aggressive incident and also was not explained in large by patient differences. Differing staff perspectives and attitudes could account for a degree of this variation (Hallett, Huber et al. 2014) as staff hold widely divergent views of the relative merits of factors that feed aggression and actions and beliefs that successfully counter aggression. External factors should also be considered as has been put forward in the Safewards model which focuses on primary and secondary prevention of aggression (Bowers 2014; Bowers, Alexander et al. 2014). Indeed, a greater focus in clinical settings on moving these interventions downstream can successfully reduce the occurrence of risky interventions with undesirable outcomes such as seclusion and restraint.

\section{References}

Abderhalden, C., I. Needham, et al. (2007). "Frequency and severity of aggressive incidents in acute psychiatric wards in Switzerland." Clin Pract Epidemiol Ment Health 3: 30.

Bacher, J., K. Wenzig, et al. (2004). SPSS twostep cluster: A first evaluation, Lehrstuhl für Soziologie.

Biancosino, B., S. Delmonte, et al. (2009). "Violent Behavior in Acute Psychiatric Inpatient Facilities: A National Survey in Italy." The Journal of Nervous and Mental Disease 197(10): 772-782 710.1097/NMD.1090b1013e3181bb1090d1096b.

Blomhoff, S., S. Seim, et al. (1990). "Can prediction of violence among psychiatric inpatients be improved." Hospital and Community Psychiatry 41(7): 771-775.

Bowers, L. (2014). "Safewards: a new model of conflict and containment on psychiatric wards." Journal of Psychiatric and Mental Health Nursing 21(6): 499-508.

Bowers, L., J. Alexander, et al. (2014). "Safewards: the empirical basis of the model and a critical appraisal." Journal of Psychiatric and Mental Health Nursing 21(4): 354-364.

Bowers, L., T. Allan, et al. (2007). "Adverse Incidents, Patient Flow and Nursing Workforce Variables on Acute Psychiatric Wards: The Tompkins Acute Ward Study." International Journal of Social Psychiatry 53(1): 75-84.

Bowers, L., A. Douzenis, et al. (2005). "Disruptive and dangerous behaviour by patients on acute psychiatric wards in three European centres." Social Psychiatry and Psychiatric Epidemiology 40(10): 822-828.

Bowers, L., A. Douzenis, et al. (2005). "Disruptive and dangerous behaviour by patients on acute psychiatric wards in three European centres." Soc Psychiatry Psychiatr Epidemiol 40(10): 822-828.

Bowers, L., J. Ross, et al. (2014). "Sexual behaviours on acute inpatient psychiatric units." J Psychiatr Ment Health Nurs 21(3): 271-279.

Bowers, L., J. Ross, et al. (2012). "The scope for replacing seclusion with time out in acute inpatient psychiatry in England." J Adv Nurs 68(4): 826-835.

Bowers, L., J. Ross, et al. (2012). "Event sequencing of forced intramuscular medication in England." Journal of Psychiatric and Mental Health Nursing 19(9): 799-806.

Bowers, L., D. Stewart, et al. (2011). Inpatient violence and aggression: a literature review. . London, Institute of Psychiatry.

Carr, V. J., T. J. Lewin, et al. (2008). "Adverse incidents in acute psychiatric inpatient units: rates, correlates and pressures." Australian and New Zealand Journal of Psychiatry 42(4): 267-282.

Cornaggia, C. M., M. Beghi, et al. (2011). "Aggression in psychiatry wards: a systematic review." Psychiatry Res 189(1): 10-20. 
Daffern, M., J. Ogloff, et al. (2003). "Aggression in an Australian forensic psychiatric hospital." The British Journal of Forensic Practice 5(4): 18-28.

Dowson, J. H., J. Butler, et al. (1999). "Management of psychiatric in-patient violence in the Anglia region: Implications for record-keeping, staff training and victim support." Psychiatric Bulletin 23(8): 486-489.

El-Badri, S. and G. Mellsop (2008). "Patient and staff perspectives on the use of seclusion." Australas Psychiatry 16(4): 248-252.

Everitt, B. S., S. Landau, et al. (2011). Hierarchical Clustering. Cluster Analysis, John Wiley \& Sons, Ltd: 71-110.

Flannery, R. B., Jr. and A. P. Walker (2001). "Characteristics of four types of patient assaults: six year analysis of the Assaulted Staff Action Program (ASAP)." Int J Emerg Ment Health 3(4): 211216.

Flannery, R. B., Jr. and A. P. Walker (2008). "Characteristics of four types of patient assaults: fifteenyear analysis of the Assaulted Staff Action Program (ASAP) with EMS implications." Int J Emerg Ment Health 10(3): 177-184.

Flood, C., L. Bowers, et al. (2008). "Estimating the costs of conflict and containment on adult acute inpatient psychiatric wards." Nurs Econ 26(5): 325-330, 324.

Foster, C., L. Bowers, et al. (2007). "Aggressive behaviour on acute psychiatric wards: prevalence, severity and management." Journal of Advanced Nursing 58(2): 140-149.

Fraley, C. and A. E. Raftery (1998). "How Many Clusters? Which Clustering Method? Answers Via Model-Based Cluster Analysis." The Computer Journal 41(8): 578-588.

Gerberich, S. G., T. R. Church, et al. (2004). "An epidemiological study of the magnitude and consequences of work related violence: the Minnesota Nurses' Study." Occupational and Environmental Medicine 61(6): 495-503.

Grassi, L., B. Biancosino, et al. (2006). "Violence in psychiatric units." Social Psychiatry and Psychiatric Epidemiology 41(9): 698-703.

Grassi, L., L. Peron, et al. (2001). "Characteristics of violent behaviour in acute psychiatric in-patients: a 5-year Italian study." Acta Psychiatrica Scandinavica 104(4): 273-279.

Gudjonsson, G., S. Rabe-hesketh, et al. (1999). "Violent incidents on a medium secure unit over a 17year period." The Journal of Forensic Psychiatry 10(2): 249-263.

Hair, J. F., W. C. Black, et al. (2010). Multivariate Data Analysis. New Jersey, Prentice Hall.

Hallett, N., J. W. Huber, et al. (2014). "Violence prevention in inpatient psychiatric settings: Systematic review of studies about the perceptions of care staff and patients." Aggression and Violent Behavior 19(5): 502-514.

Kho, K., T. Sensky, et al. (1998). "Prospective study into factors associated with aggressive incidents in psychiatric acute admission wards." The British Journal of Psychiatry 172(1): 38-43.

Labouvie-Vief, G. (2003). "Dynamic Integration: Affect, Cognition, and the Self in Adulthood." Current Directions in Psychological Science 12(6): 201-206.

Langsrud, K., O. M. Linaker, et al. (2007). "Staff injuries after patient-staff incidences in psychiatric acute wards." Nordic Journal of Psychiatry 61(2): 121-125.

Large, M. M. and O. Nielssen (2011). "Violence in first-episode psychosis: A systematic review and meta-analysis." Schizophr Res 125(2-3): 209-220.

Látalová, K. (2014). "Violence and duration of untreated psychosis in first-episode patients." International Journal of Clinical Practice 68(3): 330-335.

Mellesdal, L. (2003). "Aggression on a psychiatric acute ward: a three-year prospective study." Psychological reports 92(3c): 1229-1248.

MIND (2013). Mental health crisis care: physical restraint in crisis. A report on physical restraint in hospital settings in England.

NICE (2015). Violence clinical practice guidelines: The short-term management of disturbed/violent behaviour in in-patient psychiatric settings and emergency departments. .

Noruésis, M. J. (2011). IBM SPSS statistics 19 guide to data analysis, Pearson Education. 
Omérov, M., G. Edman, et al. (2002). "Incidents of violence in psychiatric inpatient care." Nordic journal of psychiatry 56(3): 207-213.

Owen, C., C. Tarantello, et al. (1998). "Repetitively violent patients in psychiatric units." Psychiatr Serv 49(11): 1458-1461.

Papadopoulos, C., J. Ross, et al. (2012). "The antecedents of violence and aggression within psychiatric in-patient settings." Acta Psychiatr Scand 125(6): 425-439.

Raja, M., A. Azzoni, et al. (1997). "Aggressive and violent behavior in a population of psychiatric inpatients." Soc Psychiatry Psychiatr Epidemiol 32(7): 428-434.

Ross, J., L. Bowers, et al. (2012). "Conflict and containment events in inpatient psychiatric units." J Clin Nurs 21(15-16): 2306-2315.

Soliman, A. E. and H. Reza (2001). "Risk factors and correlates of violence among acutely ill adult psychiatric inpatients." Psychiatr Serv 52(1): 75-80.

Steinert, T. (2002). "Prediction of inpatient violence." Acta Psychiatrica Scandinavica 106: 133-141.

Stewart, D. and L. Bowers (2013). "Inpatient verbal aggression: content, targets and patient characteristics." Journal of Psychiatric and Mental Health Nursing 20(3): 236-243.

Stewart, D. and L. Bowers (2015). "Substance use and violence among psychiatric inpatients." J Psychiatr Ment Health Nurs 22(2): 116-124.

Stewart, D., L. Bowers, et al. (2009). "Manual restraint of adult psychiatric inpatients: a literature review." J Psychiatr Ment Health Nurs 16(8): 749-757.

van der Mewe, M., L. Bowers, et al. (2009). Seclusion: A literature review. City University London.

Whittington, R. and T. Wykes (1994). "Violence in psychiatric hospitals: are certain staff prone to being assaulted?" Journal of Advanced Nursing 19(2): 219-225.

\section{Statement of Funding}

This paper presents independent research funded by the National Institute for Health Research (NIHR) under its Programme Grants for Applied Research programme (RP-PG-0707-10081) and supported by the NIHR Mental

Health Research Network. The views expressed are those of the author(s) and not necessarily those of the NHS, the NIHR or the Department of Health. 


\section{Aggression}

Verbal aggression

Aggression to objects

Physical aggression against others

Non-consensual sexual touching of another patient

\section{Rule breaking}

Refusing to eat

Refusing to go to bed

Refusing personal hygiene

Refusing to see workers

Refusing to get up out of bed

Exposing self

Smoking in a no-smoking area

Consensual sexual touching

\section{Absconding}

Attempted abscond

Return from abscond

Abscond

Abscond (missing without permission)

\section{Medication}

Given PRN (psychotropic)

Refusal of PRN medication

Demanding PRN medication

Refused regular medication

\section{Self-harm}

Deliberate self-harm

Suicide attempt

\section{Containment}

De-escalation

Start intermittent observations

Start constant observations

Manual restraint

Show of force

Time out

Start seclusion

Start informal/involuntary detention

Start detention

Sent to PICU or ICA

Given IM medication (forced)

Return from abscond \& continuous observation starts

Detention starts \& manual restraint

Detention starts \& seclusion starts

Seclusion starts \& manual restraint

Continuous observation ends \& intermittent starts

\section{Substance Use}

Alcohol use (suspected or confirmed)

Other substance misuse (suspected or confirmed)

\section{Containment Ends}

End intermittent observations

End constant observations

End seclusion

Returned from PICU or ICA

Informal/involuntary detention ends

\section{Substance Use}

Alcohol use (suspected or confirmed)

Other substance misuse (suspected or confirmed)

Figure 1: Conflict and Containment Events in Higher Order Categories 
